\title{
Pelvic actinomycosis: still a cause for concern
}

\author{
Aisling Susan Baird
}

\begin{abstract}
Three cases of pelvic actinomycosis, which presented over a short period of time, are described. In all three cases the diagnosis was only considered following laparotomy, although there were characteristic diagnostic clues at presentation. In two cases imaging of the pelvis by ultrasound and computed tomography was unhelpful in distinguishing the condition from pelvic neoplasia.

J Fam Plann Reprod Health Care 2005; 31(1): 73-74

(Accepted 3 November 2004)

\section{Introduction}

Although thought to be uncommon, three cases of actinomycosis presenting over a 3-month period to a gynaecological unit in a teaching hospital of 800 beds are reported. This report serves as a useful reminder for the family planning doctor making a referral and the gynaecologist contemplating laparotomy.
\end{abstract}

\section{Case reports}

Case 1

Case 1 (Table 1) was a 52-year-old multiparous housewife with frequent, heavy periods, weight loss of $8 \mathrm{~kg}$ in 2 weeks, back and lower abdominal pain for 8 days and vomiting for 4 days. A Saf-T-Coil ${ }^{\circledR}$ intrauterine contraceptive device (IUD) had been in situ for 21 years. Cervical cytology smears had all been normal, the most recent 3 years previously. Examination showed a tender mass arising out of the pelvis on the right. There was a pyrexia of $38.3^{\circ} \mathrm{C}$, total white cell count in the peripheral blood was 17.5 cells $\times 10^{9} / 1$ (with a left shift) and the Creactive protein was markedly raised at $195.7 \mathrm{mg} / \mathrm{l}$ (normal level, $<10 \mathrm{mg} / \mathrm{l})$.

A computed tomography (CT) scan demonstrated a bulky, probably fibroid, uterus containing an IUD displaced by an extensive, complex, cystic lesion in the pouch of Douglas on the left side of the pelvis and on the right side lying behind the uterus a further lesion with both cystic and solid components (Figure 1).

Five days after admission, a laparotomy was performed and a large $(110 \times 90 \times 60 \mathrm{~mm})$ left-sided ovarian mass and $(60 \times 60 \times 30 \mathrm{~mm})$ right-sided ovarian mass were found. A total abdominal hysterectomy, bilateral salpingooophorectomy and omentectomy were performed. The left-sided ovarian cyst proved to be a benign cystadenoma. Microscopy further demonstrated a severe and active chronic inflammatory process affecting the uterus and the right ovary and tube with endosalpingitis of the right tube and a tubo-ovarian abscess. Gram's and periodic acid Schiff staining showed slender actinomycotic organisms on the endometrial surface, in the right Fallopian tube and in the abscess cavities (Figure 2). There was no evidence of malignancy. The patient made a good postoperative recovery, receiving less than 1 week of antibiotic cover.

Royal Hallamshire Hospital, Sheffield, UK Aisling Susan Baird, MRCOG, MFFP, Specialist Registrar in Obstetrics and Gynaecology

Correspondence to: Dr Aisling Susan Baird, The Jessop Wing Royal Hallamshire Hospital, Tree Root Walk, Sheffield S10 2SF, UK. E-mail: aislingbaird@email.com

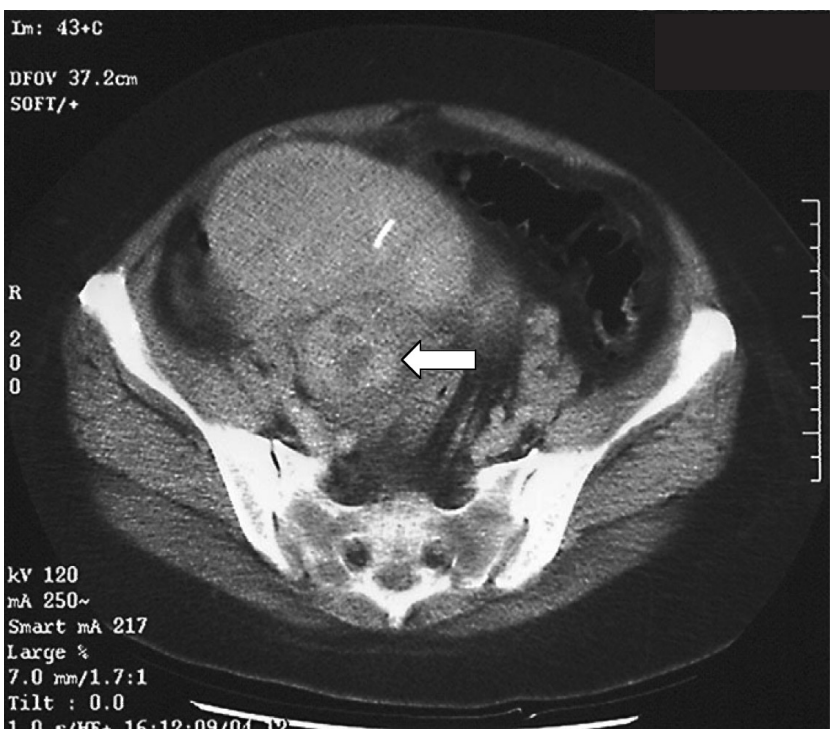

Figure 1 Computed tomography scan of the pelvis showing tubo-ovarian masses (one complex solid and cystic lesion is arrowed)

Case 2

Case 2 was a 39-year-old woman who was admitted as an emergency with abdominal pain. Following the birth of her first child in 1991, a Multiload ${ }^{\circledR}$ copper IUD had been fitted. She had a history of dyskaryotic smears and had twice undergone loop excision of the cervix for high-grade cervical intraepithelial neoplasia (CIN) between 1996 and 2001. In 2001, two cervical smear results reported actinomyces-like organisms (ALOs). Cervical biopsies in 2001 and early 2003 showed mild chronic inflammation. In mid-2003, a cone biopsy showed CIN 3 with clear excision margins and no evidence of infection. Laparascopic sterilisation and removal of the IUD were undertaken at the patient's request. No evidence of intrapelvic pathology was seen.

In October 2003, the patient was admitted as an emergency with an acute abdomen. Pelvic examination showed a bulky, tender uterus. A CT scan showed generalised ascites with oedema and inflammation at the mesenteric root, in the pelvic loops of the small bowel and in the pelvic peritoneum and abdominal fat layers. The caecum and proximal ascending colon were oedematous and thick-walled. Endocervical swabs were negative for chlamydia and other bacteria. Laparotomy revealed an

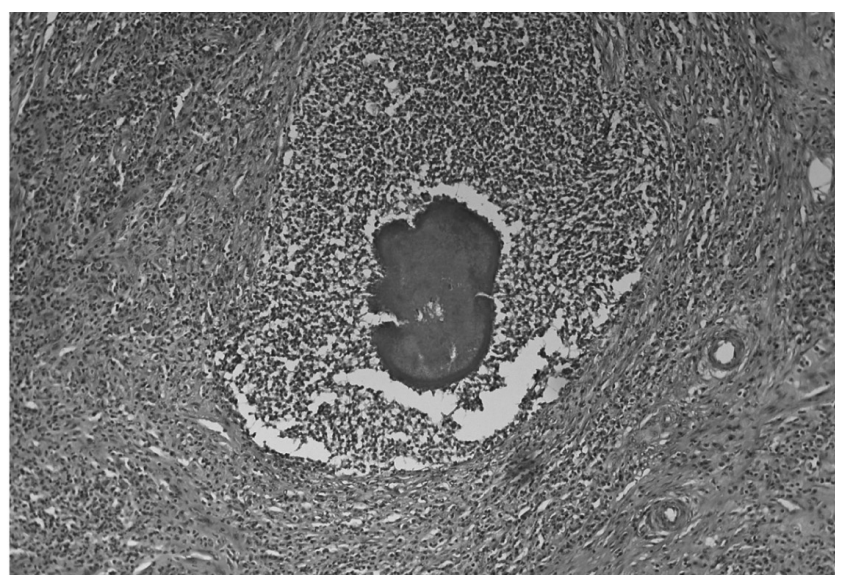

Figure 2 Actinomycosis of the ovary (haematoxylin and eosin, x100) 
CASE REPORT

Table 1 Clinical findings in three cases of pelvic actinomycosis

\begin{tabular}{|c|c|c|c|c|c|c|c|c|c|c|}
\hline \multirow[t]{2}{*}{ Case } & \multirow{2}{*}{$\begin{array}{l}\text { IUD } \\
\text { type }\end{array}$} & \multirow{2}{*}{$\begin{array}{l}\text { Years } \\
\text { in situ }\end{array}$} & \multicolumn{8}{|c|}{ Clinical finding } \\
\hline & & & $\mathrm{Hb}(\mathrm{g} / \mathrm{dl})$ & Leucocytosis & $\begin{array}{l}\text { Abdminal } \\
\text { pain }\end{array}$ & $\begin{array}{l}\text { Back } \\
\text { pain }\end{array}$ & Vomiting & $\begin{array}{l}\text { Fever and } \\
\text { weight loss }\end{array}$ & $\begin{array}{l}\text { Pelvic } \\
\text { mass }\end{array}$ & $\begin{array}{l}\text { Uterine } \\
\text { tenderness }\end{array}$ \\
\hline 1 & Plastic & 21 & 10.9 & Yes & Yes & Yes & Yes & Yes & Yes & Yes \\
\hline 3 & Copper & 1 & 10.7 & No & Yes & No & No & No & Yes & Yes \\
\hline
\end{tabular}

$\mathrm{Hb}$, haemoglobin; IUD, intrauterine device.

extensive, multilocular pelvic abscess, from which the pus grew Actinomyces israelii. Postoperative progress under prolonged antibiotic cover (cephalexin, metronidazole and doxycycline) was uneventful. Penicillin was prescribed orally for 3 months.

\section{Case 3}

Case 3 was a 35-year-old parous woman attending a gynaecological outpatient clinic with a 6-month history of intermenstrual and postcoital bleeding. Two years previously, a cervical smear had been reported as moderately dyskaryotic. Histology following loop excision of the cervix showed CIN 3 with clear excision margins and no stromal invasion.

At the outpatient clinic, an indwelling IUD was replaced with a Multiload ${ }^{\circledR} \mathrm{Cu} 375$ IUD. The uterus was noted to be tender but abdominal and vaginal examinations were otherwise unremarkable. Endocervical swabs were negative.

By 1 month, the patient had developed a constant, right-sided, lower abdominal pain disturbing sleep and daily activities. This persisted for another 4 weeks when a pelvic ultrasound scan showed a complex pelvic mass with a $5 \times 7 \times 6 \mathrm{~cm}$ loculated cystic area and a small, adjacent, solid component with an in situ IUD. CA125, blood count, electrolytes and liver function tests were all within normal limits. At laparotomy a chronic inflammatory mass involving the uterus, both ovaries and sigmoid colon was found together with an adherent omentum. The IUD was removed and biopsies were taken from the omentum and the inflammatory mass. These showed fibrotic and inflamed adipose tissue only. Actinomyces israelii was isolated from the IUD. The postoperative period was uncomplicated and a 6-week course of oral Co-amoxiclav ${ }^{\circledR}$ $375 \mathrm{mg}$ tds was prescribed.

\section{Discussion}

Clinical actinomycosis occurs by invasion and abscess formation by actinomycotic organisms in three anatomical regions: cervicofacial, thoracic and abdominal. A fastidious, slow-growing, anaerobic, Gram-positive, filamentous bacterium, the most frequently isolated species, A. israelii, is a normal commensal of the mouth, gastrointestinal and female genital tracts, and is normally of low pathogenicity. Other species implicated in clinical disease include: A. bovis, A. ericksoni, A. naeslundi, A. viscesus and $A$. odenlyticus. Invasive pelvic disease in women is usually associated with the use of an IUD, yet the simple carriage of actinomyces in the genital tract is not predictive of the development of clinical disease even if associated with an IUD. ${ }^{1,2}$ Persson and Holmberg ${ }^{3}$ found the organism in 3-4\% of women on a single vaginal culture (with and without an IUD in situ). Curtis and Pine ${ }^{4}$ found $27 \%$ vaginal carriage in women not using an IUD.

In a systematic review, Fiorino ${ }^{5}$ identified 92 cases of actinomycotic abscess associated with IUD use. The average patient was 37 years of age, had been using an IUD for 8 years and presented with abdominal pain, weight loss, vaginal discharge and fever. Laboratory studies commonly revealed anaemia, leucocytosis and an elevated erythrocyte sedimentation rate. Pelvic actinomycosis classically presents with tubo-ovarian abscess formation and is well known to mimic pelvic malignancy or inflammatory bowel disease. For this reason the diagnosis is usually made after extensive and unnecessary surgery. Classically manifest with unilateral lesions, clinical actinomycosis may present as a bilateral ovarian tumour or retroperitoneal mass. ${ }^{5}$ Imaging is not always helpful. Fiorino found the diagnosis had been made preoperatively in only $17 \%$ of cases. If suspected at presentation, actinomycosis can be successfully treated with a prolonged course of penicillin with or without minimally invasive surgery, an important consideration in young females. Fiorino was of the opinion that the recognition of common features preoperatively often spares the patient from extensive surgery.

Despite its alleged rarity, three cases of pelvic actinomycosis presented within 3 months to an English teaching hospital of 800 beds. An anaerobic bacterium of low virulence, actinomyces does not cross intact mucous membranes, and invasive disease can take several years to develop. Two of our three patients had undergone recent excision of cervical tissue: it is interesting to speculate an association. Although ALOs had been identified on cervical cytology in Case 2, neither IUD removal nor antibiotic therapy are recommended in this situation unless the woman is symptomatic.6,7 Compared with Fiorino's series the cases described here show many similarities. Yet despite characteristic presenting features, actinomycosis was not considered preoperatively and all three women underwent laparotomy before the diagnosis was revealed.

Acknowledgements

The author wishes to thank the patients concerned for permission to report these cases, Mr M E L Paterson and Mr A M Gillespie, the consultants concerned with the patients' care, and Drs Ingram, de Noronha and Smith for kindly providing scanning and histopathological images.

Statements on funding and competing interests

Funding. None identified.

Competing interests. None identified.

References

1 Persson E, Holmberg K, Dahlgren S, Nilsson L. Actinomyces israelii in the genital tract of women with and without intra-uterine contraceptiv

2 Thiery M, Claeys G, Mrozowski B, van den Broecke R, van Kets H, Parewijck W, et al. Significance of colonization of the lower female genital tract with Actinomyces israelii. IRCS Med Sci 1986; 14: 292-293.

3 Persson E, Holmberg K. A longitudinal study of Actinomyces israelii in the female genital tract. Acta Obstet Gynecol Scand 1984; 63: 207-216.

4 Curtis EM, Pine L. Actinomycetes in the vagina of women with and without intrauterine contraceptive devices. Am J Obstet Gynecol 1981; 140: 880-884.

5 Fiorino AS. Intrauterine contraceptive device-associated actinomycotic abscess and actinomycetes detection on cervical smear. Obstet Gynecol 1996; 87: 142-149.

6 Department of Health. Colposcopy and Programme Management: Guidelines for the NHS Cervical Screening Programme. NHSCSP Guidelines for the NHS Cervical Screening Programme. NHSCSP Publication No. 20, April 2004. London, UK: Department of Healt
2004. http://www.cancerscreening.nhs.uk/cervical/publications.

7 Faculty of Family Planning and Reproductive Health Care Clinical Effectiveness Unit. FPPRHC Guidance (January 2004). The copper intrauterine device as long-term contraception. J Fam Plann Reprod Health Care 2004; 30: 29-42. 